\title{
Soluble angiotensin-converting enzyme levels in heart failure or acute coronary syndrome: revisiting its modulation and prognosis value
}

\author{
Cristina Almengló ${ }^{1}$ - Marinela Couselo-Seijas ${ }^{1} \cdot$ Rosa M. Agra ${ }^{1,2,3} \cdot$ Alfonso Varela-Román ${ }^{1,2,3}$. \\ José M. García-Acuña ${ }^{1,2,3}$. Mercedes González-Peteiro ${ }^{4}$. José R. González-Juanatey ${ }^{1,2,3}$. Sonia Eiras ${ }^{1,2}$. \\ Ezequiel Álvarez ${ }^{1,2,5}$
}

Received: 4 May 2021 / Revised: 21 July 2021 / Accepted: 9 August 2021 / Published online: 16 September 2021

(c) The Author(s), under exclusive licence to Springer-Verlag GmbH Germany, part of Springer Nature 2021

\begin{abstract}
The main objective was to compare the meaning of soluble angiotensin-converting enzyme-2 (sACE2) plasma levels modulation on the prognosis of two cohorts of heart failure (HF) and acute coronary syndrome (ACS). We conducted an observational clinical study where sACE2 was measured in two cohorts of HF or ACS (102 patients each), matched by age and gender. The primary endpoint (cardiac death) and the secondary endpoints (non-fatal myocardial infarction or HF readmission) were registered during a 5-year follow-up period. Association with pharmacotherapy was studied, and the effects of cardiovascular drugs on ACE isoforms expression were analysed in human umbilical vein endothelial cells (HUVEC) in vitro. The levels of sACE2 were significantly higher in the HF than ACS cohort. sACE2 was inversely related with the leukocytes number and directly with urea levels. In the ACS cohort, sACE2 was associated with age and glycaemic parameters, but in the HF cohort, the association was with $\mathrm{N}$-terminal pro-B-type natriuretic peptide. The levels of sACE2 were related to long-term prognosis and confirmed as a non-independent predictor in the HF cohort. Soluble ACE2 was higher in patients treated with angiotensin receptors blockers and $\beta$-blockers, accordingly with losartan and metoprolol upregulation of ACE1 and ACE2 in HUVECs. Plasma levels of sACE2 were higher in HF than in ACS, independently of age and gender, and were related to long-term cardiac death in the HF cohort. Losartan and metoprolol, but not enalapril, upregulated ACE expression in endothelial cells, accordingly with higher levels of sACE2 in patients using these drugs.
\end{abstract}

Keywords Soluble angiotensin-converting enzyme- $2 \cdot$ Acute coronary syndrome $\cdot$ Chronic heart failure $\cdot$ Long-term cardiovascular prognosis $\cdot$ Pharmacotherapy

Ezequiel Álvarez

ezequiel.alvarez.castro@gmail.com

1 Instituto de Investigación Sanitaria de Santiago de Compostela (IDIS), Complexo Hospitalario Universitario de Santiago de Compostela (CHUS), SERGAS, Travesía da Choupana S/N, 15706 Santiago de Compostela, A Coruña, Spain

2 CIBERCV, Madrid, Spain

3 Servicio de Cardiología y Unidad de Hemodinámica, Complexo Hospitalario Universitario de Santiago de Compostela (CHUS), SERGAS, Travesía da Choupana S/N, 15706 Santiago de Compostela, A Coruña, Spain

4 Departamento de Enfermería, Universidad de Santiago de Compostela, 15782 Santiago de Compostela, A Coruña, Spain

5 Departamento de Farmacología, Farmacia y Tecnología Farmacéutica, Universidad de Santiago de Compostela, 15782 Santiago de Compostela, A Coruña, Spain

\section{Highlights}

- Angiotensin-converting enzyme 2 (ACE2) is a crucial counter-regulator of the renin-angiotensin-aldosterone system (RAAS).

- Soluble ACE2 levels are elevated in heart failure in comparison with the acute coronary syndrome.

- Soluble ACE2 is related to the long-term prognosis of death in heart failure.

- Levels of soluble ACE2 could be affected by angiotensin receptor blockers and B-blockers.

- Modulation of soluble ACE2 could influence the prognosis of cardiovascular patients. 


\section{Introduction}

Angiotensin-converting enzyme 2 (ACE2) is a crucial counter-regulatory enzyme that converts angiotensin II into angiotensin 1-7, which reduces blood pressure and inflammation through vasodilation, increased sodium and water renal excretion and nitric oxide production [1]. Although ACE2 expression was mainly found in the heart, kidney and gastrointestinal system, components of the renin-angiotensin-aldosterone system (RAAS) are expressed in most tissues determining its balance [2,3]. Despite the beneficial effects of ACE2, its elevated circulating levels and activity have been related to poor prognosis in patients with cardiovascular diseases. Included in these are heart failure [4-6], obstructive coronary artery disease [7], atrial fibrillation [8], aortic stenosis [9] and dilated cardiomyopathy or pulmonary hypertension [10]. Moreover, it has been recently reported that increased plasma ACE2 levels are associated with an increased risk of major cardiovascular events in the general population [11].

Although there is no consensus, drugs targeting RAAS as renin inhibitors, ACE inhibitors (ACEI), angiotensin receptor type I blockers (ARB) and aldosterone antagonists and the cardiovascular disease itself could modulate ACE2 expression and/or ACE2 activity. A significant decrease in ACE2 myocardial expression was reported in hypertensive [12] or atrial fibrillation patients [13], whereas treatment with ACEI and/or ARB could increase cardiac expression of ACE2 in patients with advanced coronary disease or heart failure (HF) [14]. The activation of ACE2 with ARB could be beneficial during post-infarction ventricular remodelling [15] due to its additional protective roles at the renal and pulmonary levels [16]. On the other hand, high levels of ACE2 expression have been reported in patients with HF [17], where high levels of soluble ACE2 (sACE2) were correlated with the severity of the disease independently of other disease states and medication used [5]. ACE2 expression could be related to left ventricular remodelling in HF [18]. On murine experimental models, treatment with ACEI and/ or ARB showed higher cardiac ACE2 activity but different effects on ACE2 expression [19].

ACE2 at the cellular membrane is exposed to the action of disintegrin and metalloproteases (ADAM), from which ADAM17 is the most extensively studied ADAM family member. This enzyme is a key mediator of cell signalling by ectodomain shedding of growth factors, cytokines, receptors and adhesion molecules at the cellular membrane, so it can induce inflammation, tissue remodelling and dysfunction associated with various cardiovascular diseases (see for a review Kawai et al. [20]). Since ACE2 is cleaved from the cells by ADAM17, it can influence the circulating ACE2 levels [21].
The apparent paradox between the beneficial effects of ACE2 activity and its relationship with poor prognosis or cardiovascular risk is also translated to the case of novel infectious coronavirus disease 2019 (COVID-19). ACE2 is the viral receptor for severe acute respiratory syndrome coronavirus 2 (SARS-CoV-2) entering the cells. However, ACE2 activity counteracts the balance of the RAAS, which participates in the progression of cardiovascular diseases of patients suffering from COVID-19 [22-24].

Taking together, this work aimed to analyse the possible role of the sACE2 plasma levels on the prognosis of ACS and HF in two age- and gender-matched cohorts previously studied on these pathologies, considering key steps of the cardiovascular disease continuum $[25,26]$. The possible influence of pharmacotherapy on ACE2 levels was also analysed with the help of in vitro experiments in human endothelial cells.

\section{Materials and methods}

\section{Subjects}

This was a prospective and observational study of two cohorts of patients with the following characteristics. The first cohort was composed of consecutive outpatients attending the HF Unit of our hospital between July 2008 and April 2009 [27]. After that, patients admitted to our coronary care unit (CCU) with ACS and fitting our inclusion criteria were included between October 2009 and January 2011 [28]. Patients from both cohorts were matched by age and gender, resulting in a final population of 204 patients (102 on each cohort). This population was previously studied for the prognosis of cardiovascular disease [29].

Inclusion criteria for patients were to have a confirmed diagnosis of HF or an ACS according to the diagnostic criteria for HF or ACS proposed by the European Society of Cardiology [30]. The exclusion criteria were pregnancy, chronic inflammatory or malignant diseases, severe kidney dysfunction (glomerular filtration rate $(\mathrm{GFR})<30 \mathrm{~mL} / \mathrm{min} / 1.73 \mathrm{~m}^{2}$ ), liver dysfunction, active or recent infections (last month) or haematological disorders or having previous major trauma or surgery (within 3 months).

In the cohort of HF, patients with acute coronary syndrome and/or who had undergone myocardial revascularisation in the previous 3 months were also excluded to avoid the influence of concomitant coronary artery disease at the moment of inclusion. In the cohort of ACS, patients with previous myocardial infarction, a history of HF, cardiomyopathy or moderate/severe valvular heart disease, prior stroke, arterial or venous thromboembolic disease or peripheral artery disease were excluded to avoid simultaneity of $\mathrm{HF}$ and previously established symptomatic ischemic 
disease. Written informed consent was obtained from each included subject according to the protocol approved by the Ethics Committee for Human Studies at Galicia (our Spanish region), following the 1975 Declaration of Helsinki and its following updates.

For all included patients, detailed information was gathered from medical history and appropriate physical examination and recorded in a database. Also, blood samples were obtained for local laboratory analysis (haemogram, basic biochemistry and coagulation rate, lipid profiles and specialised parameters, such as soluble ACE2 levels).

Peripheral venous blood was collected in EDTA-anticoagulated tubes between 8 and $10 \mathrm{AM}$ after an overnight fast in HF patients and during the $24 \mathrm{~h}$ post-infarction in the ACS cohort. Plasma was separated by centrifugation (10 min. $1800 \times g$, room temperature) and stored at $-40{ }^{\circ} \mathrm{C}$ until analysis. An electrocardiogram and echocardiogram were also performed on each patient. Definitions and laboratory data are detailed in the Supplementary Material.

\section{Follow-up and endpoints}

Follow-up data were based on patients' records available at our outpatient clinic. As noted and confirmed by a review of the death certificate, hospital chart and physician's records, the primary endpoint was cardiac death. Secondary endpoints were the incidence of non-fatal myocardial infarction, evidenced by the appropriate combination of symptoms, electrocardiogram, enzyme changes or HF readmission. The combined endpoint was the incidence of major adverse cardiovascular events (MACE; cardiac death, reinfarction or HF readmission).

\section{Cell culture}

Human umbilical vein endothelial cells (HUVEC) were isolated from freshly obtained human umbilical cords donated under informed consent from mothers, following the method previously described [31] and detailed in the Supplementary Material. All the procedures were approved by the Ethics Committee for Human Studies at Galicia (our Spanish region), according to the World Medical Association Declaration of Helsinki.

Post-confluent HUVEC cultures were treated with losar$\tan \left(100 \mu \mathrm{M}\right.$, Sigma-Aldrich ${ }^{\circledR}$, Merck Life Science S.L.U., Madrid, Spain), enalapril maleate salt (50 $\mu \mathrm{M}$, SigmaAldrich $\left.{ }^{\circledR}\right)$ or metoprolol $\left(100 \mu \mathrm{M}\right.$, Sigma-Aldrich $\left.{ }^{\circledR}\right)$ after the serum-starvation period. Angiotensin II (100 nM, SigmaAldrich $\left.{ }^{\circledR}\right)$ was used alone or combined with previous drugs to simulate states of RAAS activation. PD123319 (10 $\mu$ M, Tocris, Biotechne R\&D Systems, Madrid, Spain) was used as an angiotensin type 2 receptor antagonist in some experiments. Losartan was used as a representative ARB, enalapril as an ACEI and metoprolol as a $\beta$-blocker. The final concentrations used for each drug in the experiments have been selected after a careful revision of the bibliography about the in vitro use of these drugs in experiments with human endothelial cells. Treatments were always incubated for $10 \mathrm{~h}$.

Total RNA was obtained, quantified, reverse-transcribed and amplified as detailed in the Supplementary Materials.

\section{Protein analysis}

For ACE2 protein determination in HUVEC and cell culture supernatants, cells were serum-starved and treated as described in the previous section. Proteins were obtained after cell lysis with RIPA buffer and resolved on sodium dodecyl sulphate polyacrylamide gel electrophoresis (SDS-PAGE) for Western blotting of ACE2, as detailed in the Supplementary Materials. Quantification of sACE2 was made in the cell culture supernatants by ELISA (OriGene Technologies, Inc., Rockville, MD, USA) after $20 \times$ concentration with Amicon filters $3 \mathrm{KDa}$ (Merck Life Science S.L.U., Madrid, Spain).

\section{Data analysis}

The statistical analyses were performed with Statistical Package for the Social Sciences (SPSS), version 17.0. The categorical or dichotomous variables were expressed as absolute values and percentages and were compared with the Pearson $X^{2}$ test. In the case of continuous variables, normality was checked with the Kolmogorov-Smirnov test. When normally distributed, variables were described as the mean \pm standard deviation (SD), and when not, as the median and inter-quartile range. The student $t$-test was used to compare continuous variables between groups of patients (two tail distribution and equal variances between samples) when variables fulfilled the condition of normality, whereas the Mann-Whitney $U$ test was used when not. Continuous data from more than two groups were compared with ANOVA followed by Tukey's test. Non-normal distributed variables were compared with the Wilcoxon test for two groups or the Kruskal-Wallis test (unrelated data) or Friedman test (related data) to compare more than two groups. Correlations between variables were calculated by Pearson's or Spearman's tests to whether the data were normally distributed or not, respectively. Regression analyses, linear for continuous variables and logistic for dichotomous variables, were performed to find the independent variables related to SACE2 levels. The predictive value of individual variables for new cardiovascular events was analysed by receiver operating characteristic (ROC) curves. Different Cox proportional hazard analyses were carried out to assess the independence of SACE2 levels to predict MACE, and data were presented as hazard ratios (HR) with 95\% confidence intervals. Kaplan-Meier curves (analysed with the log-rank test) were performed to evaluate the prognostic 
value of sACE2 during follow-up. The mRNA and protein levels were expressed as the fold change of each treatment with respect to the control treatment as mean \pm standard error of the mean (SEM). Data expressed as percentages or fold changes were to control for unwanted sources of variation. A $p$-value of $<0.05$ was considered statistically significant.

\section{Results}

\section{Baseline characteristics}

A total of 204 consecutive patients fulfilling the inclusion criteria and distributed in two cohorts of 102 ageand gender-matched HF or ACS patients were included in the study (Fig. 1). Basal characteristics in the moment of the inclusion are presented in Table 1. The mean age for the total population was $69.4 \pm 11.7$ years, and $32 \%$ were female. An expected statistical difference between cohorts was observed for patients with reduced LVEF (LVEF $<40 \%)$ and mid-range ejection fraction (LVEF 40-49\%), which were higher in the HF cohort. Patients in the HF cohort showed higher body mass index, more dyslipidaemia and worse glycaemic control, whereas in the ACS cohort were more smokers and presented lower HDL levels.

Attending to the medication that could be compared in both cohorts, patients with HF were in treatment with ACEI, $\beta$-blockers and acetylsalicylic acid (ASA) more than patients with ACS at the moment of inclusion. ARB was considered here by their possible implication in the levels of ACE2. However, in the ACS cohort, these drugs are used to substitute ACEI when these are not well tolerated. Therefore, in the small number of patients of our cohort, there were no treatments with ARB.
Fig. 1 Consort flow diagram of the study. Flow diagram of the study. ACE2 angiotensinconverting enzyme- 2

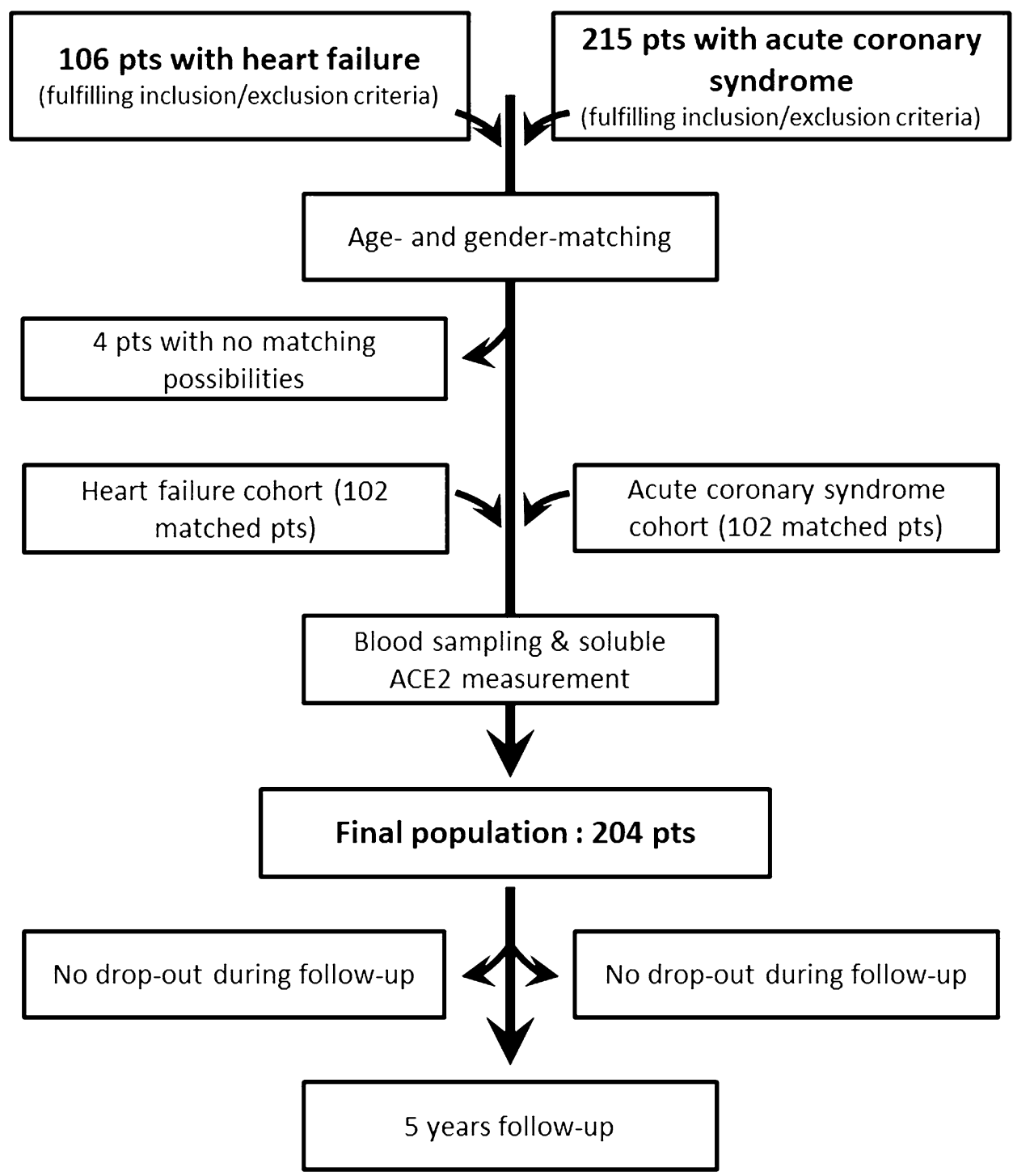


Table 1 Baseline characteristics of the patients stratified by cohorts

\begin{tabular}{|c|c|c|c|}
\hline Variable & HF cohort $(n=102)$ & ACS cohort $(n=102)$ & $p$ value* \\
\hline \multicolumn{4}{|l|}{ Anthropometry } \\
\hline Age, years & $69.5 \pm 11.8$ & $69.3 \pm 11.6$ & 0.919 \\
\hline Female, $\%(n)$ & $33.3(34)$ & $30.4(31)$ & 0.652 \\
\hline BMI, $\mathrm{kg} / \mathrm{m}^{2}$ & $28.2 \pm 4.2$ & $26.4 \pm 3.4$ & 0.006 \\
\hline Leukocytes, $10^{3} / \mu \mathrm{L}$ & 7.17 [5.94-8.89] & 8.89 [7.24-12.30] & $<0.001$ \\
\hline \multicolumn{4}{|l|}{ Vascular risk } \\
\hline $\mathrm{HT}, \%(n)$ & $64.7(66)$ & $58.8(60)$ & 0.387 \\
\hline DLP, \% $(n)$ & $60.4(61)$ & $46.1(47)$ & 0.041 \\
\hline $\mathrm{DM}, \%(n)$ & $36.3(37)$ & $33.3(34)$ & 0.659 \\
\hline Smokers, \% (n) & $7.8(8)$ & $21.6(22)$ & 0.006 \\
\hline \multicolumn{4}{|l|}{ Cardiac function } \\
\hline Heart rate, bpm & $74.0[63.0-85.0]$ & $71.5[60.0-87.2]$ & 0.618 \\
\hline mrLVEF, \% (n) & $12.1(12)$ & $16.6(17)$ & $<0.001$ \\
\hline rLVEF, \% (n) & $63.6(63)$ & $17.6(18)$ & \\
\hline NTproBNP, pg/mL & $1602.0[741.2-3097.0]$ & - & - \\
\hline \multicolumn{4}{|l|}{ Kidney function } \\
\hline $\mathrm{eGFR}, \mathrm{mL} / \mathrm{min} / 1.73 \mathrm{~m}^{2}$ & $67.5 \pm 21.4$ & $79.1 \pm 16.1$ & $<0.001$ \\
\hline Urea, mg/dL & $59.0[42.0-78.0]$ & $43.0[35.0-53.0]$ & $<0.001$ \\
\hline \multicolumn{4}{|l|}{ Glycaemic control } \\
\hline Glycaemia, mmol/L & $6.16[5.49-7.44]$ & 7.44 [6.23-10.94] & $<0.001$ \\
\hline Fructosamine, mmol/L & $236.0[201.0-310.5]$ & $182.0[156.5-253.0]$ & $<0.001$ \\
\hline $\mathrm{HbA} 1 \mathrm{C}, \%$ & $6.0[5.7-7.3]$ & $5.7[5.5-6.7]$ & 0.028 \\
\hline \multicolumn{4}{|l|}{ Blood lipids } \\
\hline $\mathrm{TC}, \mathrm{mmol} / \mathrm{L}$ & $4.66[4.06-5.48]$ & $4.74[3.96-5.59]$ & 0.962 \\
\hline $\mathrm{LDL}, \mathrm{mmol} / \mathrm{L}$ & $2.84[2.16-3.43]$ & $2.92[2.11-3.42]$ & 0.798 \\
\hline $\mathrm{HDL}, \mathrm{mmol} / \mathrm{L}$ & $1.06[0.83-1.29$ & $0.92[0.72-1.20]$ & 0.032 \\
\hline $\mathrm{TG}, \mathrm{mmol} / \mathrm{L}$ & $1.16[0.78-1.56]$ & $1.34[0.93-1.79]$ & 0.074 \\
\hline \multicolumn{4}{|l|}{ ACE2 } \\
\hline sACE2 (pg/mL) & $2334.3 \pm 1741.4$ & $1680.0 \pm 1186.1$ & 0.002 \\
\hline \multicolumn{4}{|l|}{ Pharmacotherapy } \\
\hline ACEI, \% $(n)$ & $74.5(76)$ & $35.3(36)$ & $<0.001$ \\
\hline $\mathrm{ARB}, \%(n)$ & $19.6(20)$ & - & - \\
\hline$\beta$-blockers, $\%(n)$ & $86.3(88)$ & $8.8(9)$ & $<0.001$ \\
\hline ASA, $\%(n)$ & $36.3(37)$ & $15.7(16)$ & 0.001 \\
\hline OAD, \% (n) & $26.5(27)$ & $17.6(18)$ & 0.088 \\
\hline Insulin, \% (n) & $9.8(10)$ & $7.8(8)$ & 0.403 \\
\hline
\end{tabular}

The $p$-values $<0.05$ are in bold cases to highlight their statistical significance. ACEI angiotensin-converting enzyme inhibitors, $A R B$ angiotensin receptor type I blockers, $A S A$ acetylsalicylic acid, BMI Body Mass Index, $D L P$ dyslipidaemia, $D M$ diabetes mellitus, $e G F R$ estimated glomerular filtration rate, $H b A 1 C$ glycated haemoglobin, $H D L$ high-density lipoprotein cholesterol, $H T$ hypertension, $L D L$ low-density lipoprotein cholesterol, $m r L V E F$ mid-range left ventricular ejection fraction, $N T p r o B N P \mathrm{~N}$-terminal pro-B-type natriuretic peptide, $O A D$ oral antidiabetics, $r L V E F$ reduced left ventricular ejection fraction, $s A C E 2$ soluble angiotensin-converting enzyme-2, $T C$ total cholesterol, $T G$ triglycerides

* Statistically difference between cohorts: $p$ value for Student's $t$ test or Mann-Whitney $U$ test for normal and non-normal, respectively when continuous variables; Pearson $X^{2}$ test for categorical variables

\section{Soluble ACE2}

sACE2 plasma levels were higher in the HF cohort than in the ACS cohort. No differences in this parameter were found regarding hypertension, dyslipidaemia, diabetes or gender.
However, this soluble enzyme was lower in the 29 smokers of the population than non- and ex-smokers $(1476.8 \pm 764.7$ vs. $2105.7 \pm 1606.0 \mathrm{pg} / \mathrm{mL}$ for smokers and non-smokers, respectively; $p=0.001$ ). 
Considering the total population, no significant associations were observed between sACE2 levels and any other parameter measured, except for the number of leukocytes, where an inverse relationship was shown (Supplementary Figure S1). Analysing each cohort separately, sACE2 levels were significantly related with NTproBNP in the HF cohort (Supplementary Figure S2), and in the ACS cohort, there were positive associations with age and glycaemic parameters (glycaemia, fructosamine and glycated haemoglobin; Supplementary Figure S3).

No differences in SACE2 levels were observed for the treatment with or without ACEI. The levels of the enzyme trended to be higher in patients using ARB $(p=0.138)$. However, only the HF cohort could be analysed in this regard, and only 20 patients were under treatment with this type of drug. We found higher levels of SACE2 in patients under treatment with $\beta$-blockers, although the percentage of use of these drugs in each cohort is quite different $(86 \%$ in $\mathrm{HF}$, $9 \%$ in ACS).

Variables predicting SACE2 levels by linear univariate regression analyses were leukocytes concentration, smoking habit, reduced LVEF, blood levels of urea, NTproBNP and $\beta$-blockers use (Supplementary Table S1). The combination of these variables in a multivariate analysis adjusted by age and gender showed that only NTproBNP was an independent predictor of sACE2 plasma levels in HF. In the ACS cohort, NTproBNP levels were not available, and the independent predictor was age (Supplementary Table S2).

Logistic regression analyses were performed to identify the best indicators of elevated sACE2 levels $(>1600 \mathrm{pg} /$ $\mathrm{mL}$ ). The levels of NTproBNP (HR 1.000 [1.000-1.001] 95\% CI; $p=0.011$ ), urea (HR 1.029 [1.014-1.044] 95\% CI; $p<0.001$ ) and $\beta$-blockers use (HR 1.802 [1.020-3.185] $95 \% \mathrm{CI} ; p=0.043$ ) were the only variables predicting the enhanced levels of sACE2. In the multivariate model adjusting by age and gender, only NTproBNP maintained its independence (HR 1.000 [1.000-1.001] 95\% CI; $p<0.011$ ).

Continuous urea levels were a better predictive variable than dichotomous conversion to high $(>40 \mathrm{mg} / \mathrm{dL})$ or normal values $(<40 \mathrm{mg} / \mathrm{dL})$, suggesting that the metabolic meaning of urea levels, more than its clinical interpretation, affects sACE2 levels.

\section{Follow-up and prognosis}

The median follow-up of event-free patients was 5.0 years. None of the 204 patients was lost to follow-up. A total of 54 cardiac deaths (39 in HF and 15 in ACS cohort) and 88 events (56 in HF and 32 in ACS cohort) were registered. The clinical parameters with statistically significant differences for the events and event-free groups of patients on each cohort are presented in Table 2. The rest of the clinical parameters are included in Supplementary Table S3. Patients with events in the HF cohort showed more incidence of reduced LVEF and GFR and higher NTproBNP and sACE2 levels. In the ACS cohort, more patients presented reduced LVEF, were diabetic and presented higher glycated haemoglobin levels and lower body mass index, but no differences were observed in SACE2 levels. Urea blood levels were higher in the group with events in both cohorts. The clinical parameters stratified by the type of event (death or secondary events) in the event-group of each cohort are presented in Supplementary Table S4.

The value of sACE2 levels to predict new events during the follow-up period was analysed by receiver operating characteristic (ROC) curves in each cohort. Interestingly, sACE2 levels presented statistically significant areas under the ROC curves for cardiac death $(0.62395 \%$ CI $(0.505-0.740), p=0.041)$, secondary events $(0.64495 \%$ CI $(0.535-0.754), p=0.014)$ or MACE including death $(0.64795 \%$ CI $(0.538-0.756), p=0.012)$ in the HF cohort.

Table 2 Baseline characteristics of patients with statistically significant differences, stratified by event and event-free group in the two cohorts

\begin{tabular}{|c|c|c|c|c|c|c|}
\hline \multirow[t]{2}{*}{ Variable } & \multicolumn{3}{|l|}{ HF cohort } & \multicolumn{3}{|l|}{ ACS cohort } \\
\hline & Event free $(n=45)$ & Event (MACE) $(n=57)$ & $p$ value* & Event free $(n=69)$ & Event (MACE) $(n=33)$ & $p$ value* \\
\hline Age, years & $66.2 \pm 11.8$ & $72.1 \pm 11.3$ & 0.011 & $68.0 \pm 11.8$ & $72.0 \pm 10.6$ & 0.098 \\
\hline $\mathrm{DM}, \%(n)$ & $28.9(13)$ & $42.1(24)$ & 0.168 & $26.1(18)$ & $48.5(16)$ & 0.025 \\
\hline rLVEF, \% (n) & $52.3(23)$ & $72.7(40)$ & 0.029 & $13.0(9)$ & $30.3(10)$ & 0.037 \\
\hline NTproBNP, pg/mL & 906.0 [272.2-1767.5] & 2461.5 [1351.0-5178.0] & $<0.001$ & - & - & - \\
\hline BMI, $\mathrm{kg} / \mathrm{m}^{2}$ & $28.5 \pm 4.6$ & $27.9 \pm 4.0$ & 0.584 & $26.9 \pm 3.4$ & $25.4 \pm 10.6$ & 0.046 \\
\hline $\mathrm{eGFR}, \mathrm{mL} / \mathrm{min} / 1.73 \mathrm{~m}^{2}$ & $73.2 \pm 20.4$ & $63.2 \pm 21.3$ & $\mathbf{0 . 0 2 0}$ & $80.7 \pm 16.0$ & $75.8 \pm 16.2$ & 0.161 \\
\hline Urea, mg/dL & $54.0[40.0-66.0]$ & $67.5[47.2-86.5]$ & 0.001 & $41.0[34.5-50.0]$ & $50.5[38.2-59.0]$ & 0.028 \\
\hline HbA1C, \% & $6.0[5.7-6.7]$ & $6.0[5.7-7.9]$ & 0.529 & $5.7[5.4-6.3]$ & $6.1[5.5-7.6]$ & 0.043 \\
\hline sACE2 (pg/mL) & $1887.0 \pm 1608.6$ & $2677.7 \pm 1775.1$ & 0.024 & $1611.9 \pm 1007.8$ & $1829.7 \pm 1516.1$ & 0.477 \\
\hline
\end{tabular}

The $p$-values $<0.05$ are in bold cases to highlight their statistical significance

*Statistically difference between cohorts: $p$ value for Student's $t$ test or Mann-Whitney $U$ test for normal and non-normal, respectively when continuous variables; Pearson $\mathrm{X}^{2}$ test for categorical variables. Abbreviations: as in Table 1 
From these analyses, a cutoff point was defined for sACE2 concentration in plasma of $1600 \mathrm{pg} / \mathrm{mL}(\sim 0.650$ sensitivity, $\sim 0.580$ specificity). However, sACE2 levels were not predictive for any kind of event analysed by ROC curves in the ACS cohort.

Kaplan-Meier survival curves were constructed using the cutoff value defined for the sACE2 variable $(1600 \mathrm{pg} / \mathrm{mL})$ separately for the three types of endpoints (death, secondary events and the combination of both) in the HF cohort. In the cases of secondary events and the combination of death and secondary events, the sACE2 cutoff value showed a tendency to significance by the log-rank test ( $p=0.070$ and $p=0.051$ for secondary events and the combined endpoint, respectively). However, in the case of death, the separation of survivals from non-survivals by the sACE2 cutoff value $(1600 \mathrm{pg} / \mathrm{mL})$ was statistically significant ( $p=0.028$; Fig. 2).

Although sACE2 levels, considered a continuous variable, showed a significant value for predicting secondary events $(p=0.030)$ and the combination of MACE $(p=0.030)$ by the univariate Cox regression tests in the HF cohort, they did not reach statistical significance in the multivariate regression models for long-term prognosis adjusted by age, gender, diabetes mellitus, reduced GFR and reduced LVEF.

\section{Effects of pharmacotherapy on ACE expression in HUVEC cultures}

To clarify the direct effects of ACEI, ARB and $\beta$-blockers on the gene expression levels of ACE1, ACE2 and ADAM17 (disintegrin and metalloproteinase domain-containing protein 17) in the endothelium, treatments with losartan $(100 \mu \mathrm{M}$, an ARB), enalapril (50 $\mu \mathrm{M}$, an ACEI) and metoprolol $(100 \mu \mathrm{M}$, a $\beta$-blocker) were made in HUVEC cultures for $10 \mathrm{~h}$. Cell viability in these conditions was confirmed by optical inspection of the cultures compared to control experiments and by total mRNA quantification of the cell content (no statistical differences were observed between treatments; Supplementary Table S5).

In these experiments, losartan and metoprolol induced statistically significant enhancements of the mRNA expression of the three proteins (Fig. 3). Enalapril had no significant effects on the expression of ACE1, ACE2 and ADAM17, at the mRNA level.

In a series of experiments, angiotensin II $(100 \mathrm{nM})$ was used to stimulate the endothelial cells mimicking the activation induced by the RAAS in vivo. This condition did not modify the mRNA levels of any of the proteins. Losar$\tan$ treatment $(100 \mu \mathrm{M})$, in the presence of angiotensin II $(100 \mathrm{nM})$, maintained the overexpression of ACE1, ACE2 and ADAM17 with respect to the control and angiotensin II treatments (Fig. 3). On the contrary, enalapril $(50 \mu \mathrm{M})$, in addition to angiotensin II $(100 \mathrm{nM})$, did not modify the expression of any of the proteins, so the effects were not different from the control and angiotensin II treatments.

The possible modulation of the angiotensin II effects through its type 2 receptor was analysed with PD123319, a selective antagonist of the type 2 receptor of angiotensin II. This drug did not modify the mRNA expression of ACE1 and 2 directly but reduced the levels of ADAM17 (Fig. 4). However, PD123319 did not modify the losartan-induced overexpression of ACE1, ACE2 and ADAM17, or the losar$\tan$-induced overexpression in the presence of angiotensin II of any of the three proteins (Fig. 4).

The findings on mRNA expression of ACE2 were confirmed in protein expression levels in two ways. ACE2 protein content was assessed by Western blot in HUVEC cultures treated with losartan $(100 \mu \mathrm{M})$, angiotensin II $(100 \mathrm{nM})$, and their combinations, and with metoprolol $(100 \mu \mathrm{M})$. In these experiments, losartan and metoprolol significantly enhanced the protein expression of ACE2
Fig. 2 Survival curves. KaplanMeier curves for cardiac death survival and the results of the log-rank test for the stratification by $1600 \mathrm{pg} / \mathrm{mL}$ sACE2 level $\mathbf{a}$ in $\mathrm{HF}$ and $\mathbf{b}$ in ACS
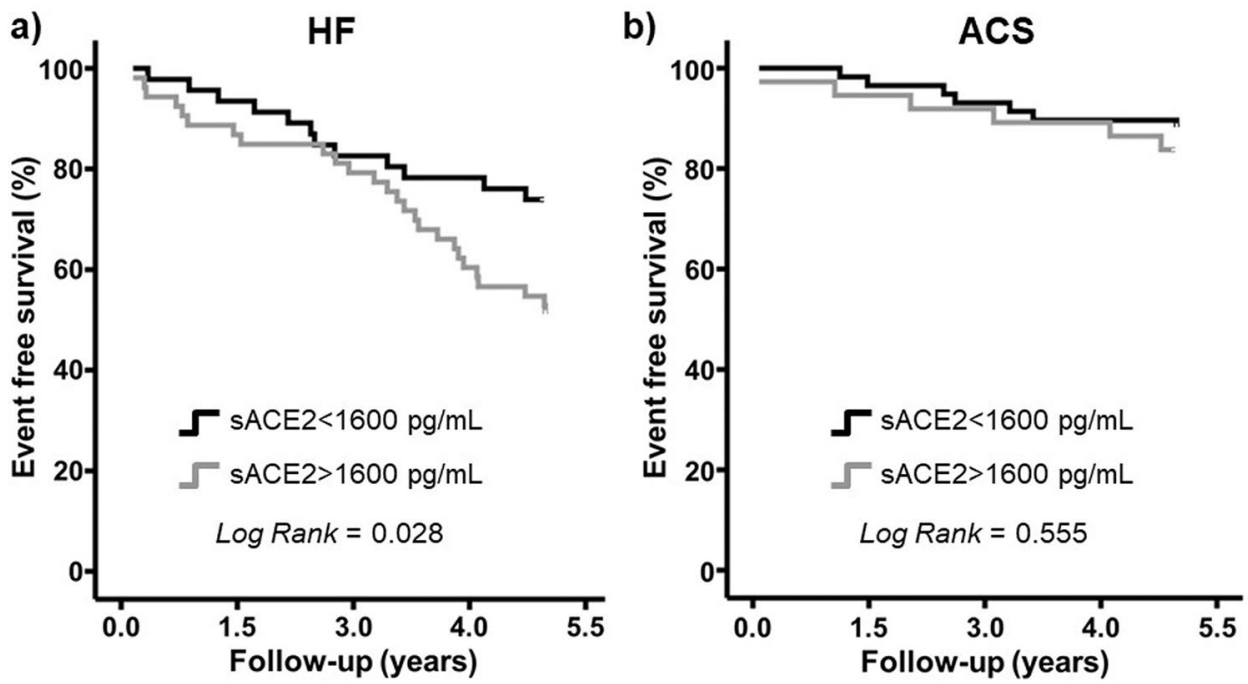

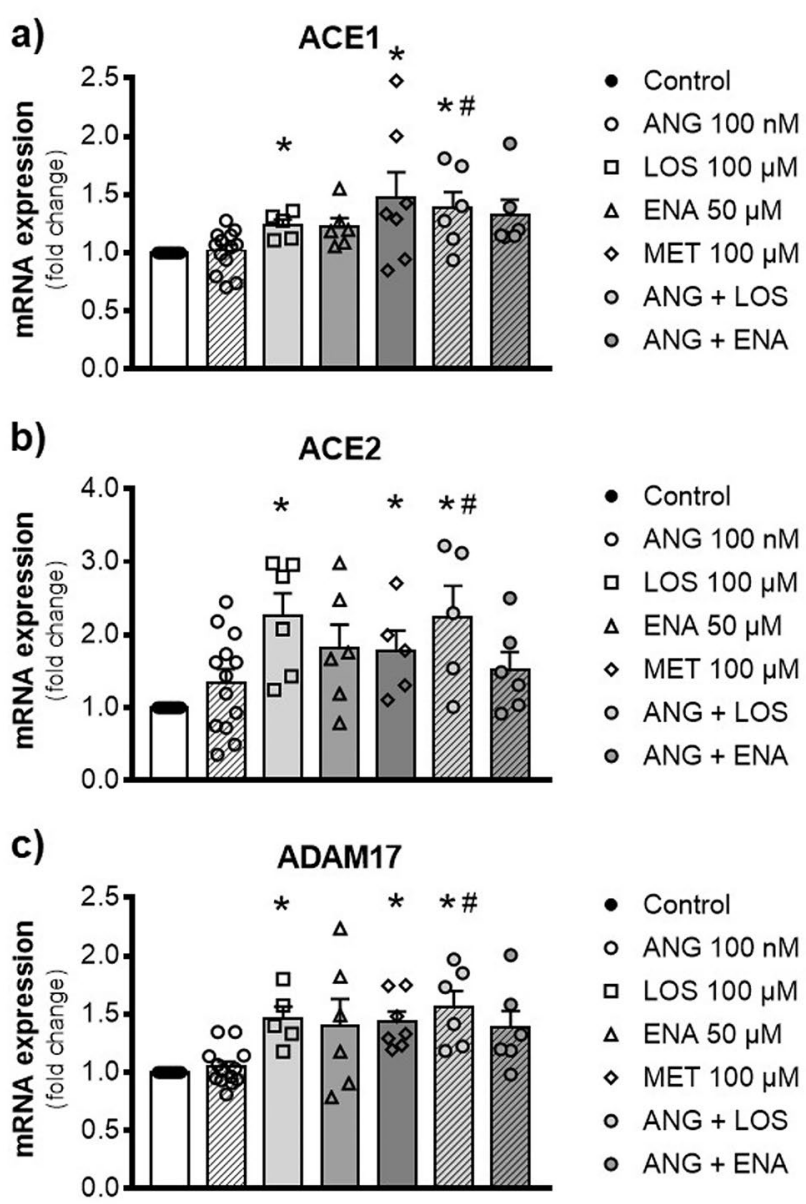

Fig. 3 Losartan upregulated ACE isoforms and ADAM17 expression. Gene expression by mRNA content, of a ACE1, b ACE2 and c ADAM17, measured under control conditions or after treatment with angiotensin II (ANG, $100 \mathrm{nM})$, losartan (LOS, $100 \mu \mathrm{M})$, enalapril (ENA, $50 \mu \mathrm{M})$, metoprolol (MET, $100 \mu \mathrm{M})$ or their combination. Columns represent the mean fold change with respect to control $(n=5) \pm$ SEM shown in vertical bars. ${ }^{*} p<0.05$ with respect to control; \# $p<0.05$ vs. ANG

(Fig. 5). Moreover, sACE2 levels were measured in the supernatant of HUVEC cultures treated with losartan $(100 \mu \mathrm{M})$, enalapril $(50 \mu \mathrm{M})$, metoprolol $(100 \mu \mathrm{M})$ and PD123319 $(10 \mu \mathrm{M})$, alone or in combination with angiotensin II $(100 \mathrm{nM})$. The levels of sACE2 were significantly higher after losartan or metoprolol treatment with respect to the control, and the effect of losartan was also maintained in the presence of angiotensin II (Fig. 5). Interestingly, PD123319 blocked the losartan + angiotensin IIinduced overexpression of sACE2 (Fig. 4; $260.7 \pm 70.5$ vs $57.5 \pm 10.1 \mathrm{pg} / \mathrm{mL}$ for angiotensin II + losartan and angiotensin II + losartan + PD123319, respectively; $p<0.05$ ).
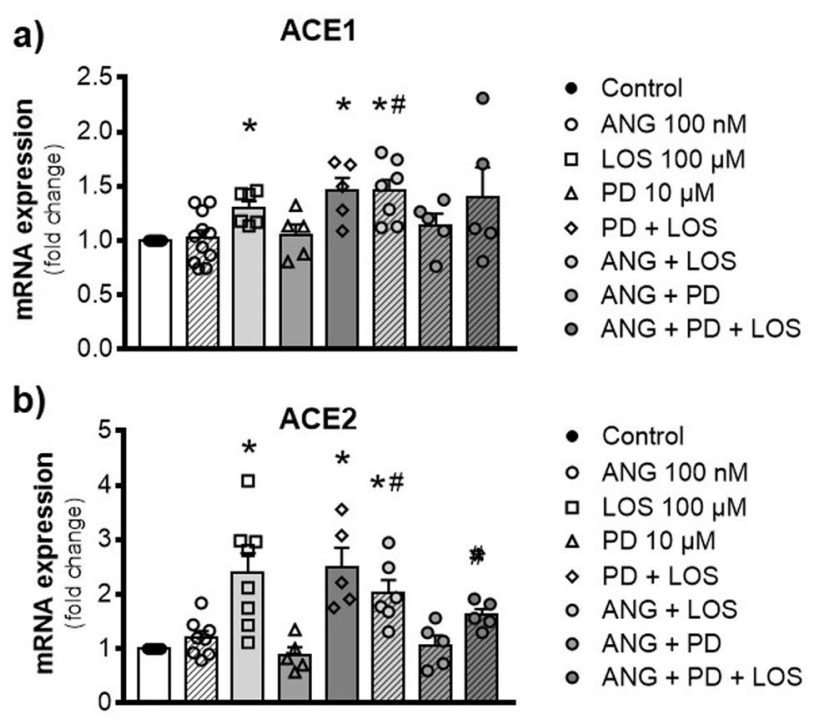

- Control

- ANG $100 \mathrm{nM}$

․ $\operatorname{LOS} 100 \mu \mathrm{M}$

$\triangle \mathrm{PD} 10 \mu \mathrm{M}$

$\diamond P D+$ LOS

- ANG + LOS

- $A N G+P D$

- $A N G+P D+L O S$

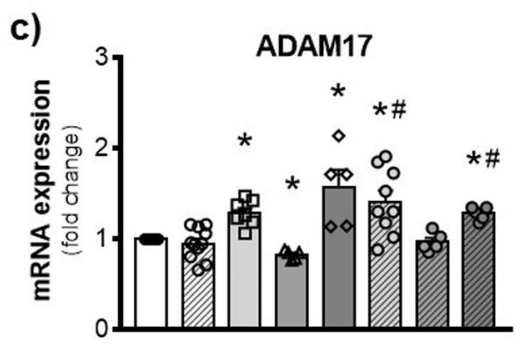

- Control

- ANG $100 \mathrm{nM}$

- $\operatorname{LOS} 100 \mu \mathrm{M}$

$\Delta \mathrm{PD} 10 \mu \mathrm{M}$

$\diamond P D+L O S$

- ANG + LOS

- $A N G+P D$

- $A N G+P D+L O S$

Fig. 4 Losartan-induced overexpression is independent of angiotensin receptors. Gene expression by mRNA content, of a ACE1, b ACE2 and c ADAM17, measured under control conditions or after treatment with angiotensin II (ANG, $100 \mathrm{nM})$, losartan (LOS, $100 \mu \mathrm{M})$, PD123319 (PD, $10 \mu \mathrm{M}$ ), or their combination. Columns represent the mean fold change with respect to control $(n=5) \pm$ SEM shown in vertical bars. $* p<0.05$ with respect to control; \#p<0.05 vs. ANG

\section{Discussion}

Here, for the first time, the meaning of the sACE2 plasma levels have been prospectively analysed in two age- and gender-matched cohorts of HF and ACS. The levels of sACE2 were significantly higher in HF than in ACS. Importantly, they were significantly related to NTproBNP levels, confirming their relationship with HF severity and long-term prognosis in the HF cohort. A cutoff value for sACE2 $(1600 \mathrm{pg} / \mathrm{mL})$ was obtained and confirmed as predictive of long-term (5 years) death in the HF cohort. However, this predictive value was not independent of other variables as age or LVEF. Pharmacotherapy with ACEI did not influence sACE2 plasma levels in both cohorts, but ARB or $\beta$-blockers could enhance ACE2 expression in the endothelium and blood. Therefore, in vitro results confirmed that ACEI (enalapril) did not modify the expression levels of ACE isoforms or ADAM17 in HUVECs. However, losartan (an ARB) and metoprolol (a $\beta$-blocker) markedly stimulated the expression of ACE isoforms, 
Fig. 5 Protein levels of ACE2 and sACE2. a Protein expression by Western blot is shown for ACE2 measured in HUVEC (representative images in the upper panel) after an incubation period with control or treatments with angiotensin II (ANG, $100 \mathrm{nM})$, losartan (LOS, $100 \mu \mathrm{M}$ ), metoprolol $(100 \mu \mathrm{M})$ or their combination. Densitometric analysis of results is shown in the lower panel as the ACE2/ $\beta$-actin ratio. $\mathbf{b}$ Protein concentration of sACE2 measured by enzymelinked immunosorbent assay in the supernatant of HUVEC after treatment with angiotensin II (ANG, $100 \mathrm{nM})$, losartan (LOS, $100 \mu \mathrm{M}$ ), enalapril (ENA, $50 \mu \mathrm{M}$ ), metoprolol $(100 \mu \mathrm{M})$, PD123319 (PD, $10 \mu \mathrm{M})$ or their combination. Columns represent mean values $(n=3) \pm$ SEM shown in vertical bars. ${ }^{*} p<0.05$ with respect to control; \#p<0.05 vs. ANG
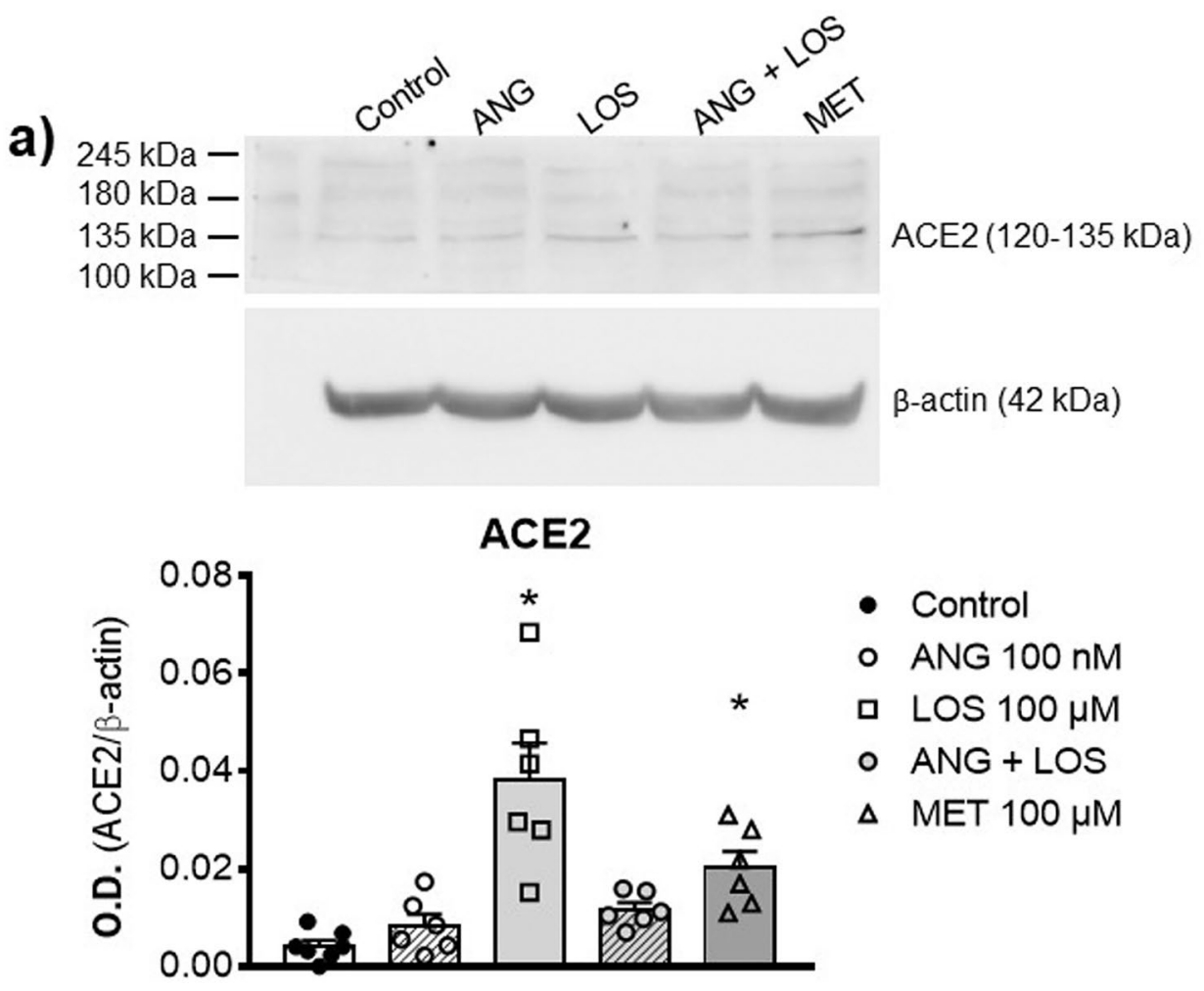

b)

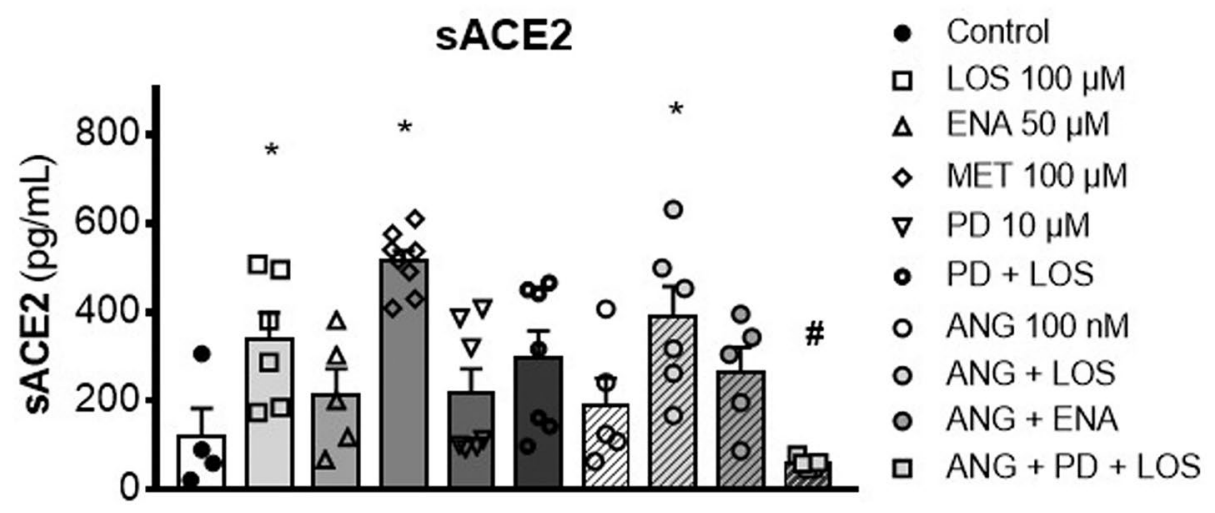

ADAM17 and sACE2, independently of the action of angiotensin II.

Although some previous reports showed higher levels of sACE2 in men than in women [4], this relationship was not confirmed in our population. In our study, it seems that the pathophysiologic process of HF increases the levels of sACE2 to counteract the RAAS exacerbation that is described to occur in HF. High levels of ACE2 expression have been reported in HF patients [14], which could be related to left ventricular remodelling in HF [18]. Increasing sACE2 plasma activity was also directly associated with the clinical diagnosis of HF and worsening of LVEF $[5,6]$. The higher levels of sACE2 also correlate with the severity of HF, independently of other disease states and medication used [5]. In agreement, we observed a clear relationship between sACE2 and NTproBNP levels. However, we do not know if HF enhances the expression of ACE2 at the membrane and soluble levels simultaneously. Previous works point to the possibility of angiotensin II promoting ACE2 proteolytic cleavage, suggesting that elevated plasma levels of sACE2 could represent the loss of its protective effects in the heart [32]. In our in vitro experiments, a direct correlation between the expression levels of ACE2 at the mRNA level, protein level and sACE2 were observed, but angiotensin II did not increase sACE2. 
We did not observe an increase in sACE2 levels in the ACS cohort, whereas the elevation of sACE2 activity was reported in patients with an acute myocardial infarction after 7 days [33]. The main explanation for our data is that blood samples for our analysis were collected in the first $24 \mathrm{~h}$ post-ACS, so we could not detect the possible increase in sACE2 levels within the week after ACS. Due to our different designs, we could only explore the possible prognostic value of early sACE2 levels in the evolution or recovery after an ACS. However, in our study, elevated concentrations of SACE2 were not related to the prognosis in patients after an ACS. No data were found in this regard on previous studies about SACE2 levels, but in a recent study with 79 patients, sACE2 activity could predict adverse long-term cardiovascular outcomes in patients with established obstructive coronary artery disease [7].

Regression analyses were performed to find the variables related to SACE2 levels. The more consistent models pointed to high urea blood levels, $\beta$-blockers use and NTproBNP levels as the main variables predicting the increase of sACE2. However, only NTproBNP was an independent predictor. The close relationship between the use of $\beta$-blockers in HF could help to explain the association with high sACE2 levels, but further research is needed to define if it is HF or the medication the reason for the sACE2 modification, as we will discuss below.

It should also be considered that levels of sACE2 were inversely related with the total number of leukocytes considering the whole population, but not in the cohorts separately. This could relate the elevation of sACE2 levels to a reduced or exhausted immunity response, but no data is available for this relationship. However, this could help to understand the association found between sACE2 levels and cardiac death in the HF cohort as it will be commented then.

The levels of ACE2, soluble or attached to the cytoplasmic membrane, have been a matter of discussion regarding their influence in the infection by SARS-CoV-2 in cardiovascular patients. This virus uses ACE2 as a viral receptor [34], so ACE2 anchored to the cellular membrane will serve as the way to enter the cells, whereas sACE2 is speculated to serve as a cleaning system of the virus, preventing viruses from entering the cell [22]. Therefore, ACE2 could increase its significance in cardiovascular patients of the COVID-19 era.

In our study, the sACE2 plasma levels were higher in patients on $\beta$-blockers. This observation could be influenced by the marked use of these drugs in HF compared to patients in the ACS cohort, but our experimental data point in the opposite direction. Interestingly, we showed that ACEI treatment does not influence sACE2 levels in patients. This finding does not directly correlate with previous findings in murine models [10], but it agrees with recent clinical studies [4]. So, it was important to confirm the behaviour of ACEI in the in vitro experiments. Our results with enalapril in HUVEC showed no modification of the expression levels of any ACE isoform, and no modification of ADAM17, a metalloprotease that has been involved in the cleavage of sACE2 [35]. However, our data suggest that further investigations should be conducted to clarify the possible relationship between ARB or $\beta$-blockers medication and sACE2 levels. In the in vitro experiments, losartan and metoprolol markedly enhanced the expression of ACE1, ACE2 and ADAM17 and even increased sACE2 concentration in the supernatant. The effect of losartan seems to be a pleiotropic direct effect since its action is also maintained in the presence of angiotensin II or the inhibition of angiotensin receptor type I, suggesting that the angiotensin receptor blocking is not the mechanistic action for ACE upregulation. In the case of metoprolol, the increased levels of sACE2 observed in patients treated with $\beta$-blockers agree with the increased expression of all forms of ACE2 at the cellular level. This important finding needs to be confirmed in future clinical studies because it is still an unsolved question [36]. Recent results point to a possible upregulation of ACE2 by ACEI and ARB in the heart of cardiovascular patients [15] or human type-II pneumocytes [37], and others do not find an association between medication and ACE2 expression [38]. However, nothing has been done, to the best of our knowledge, about the possible influence of $\beta$-blockers on ACE2 expression. Our data suggest, for the first time, the possible enhancement of ACE isoforms by these drugs, something that could be related to the increase of sACE2 in HF patients, where this medication is routinely used.

In any case, the levels of ACE2, soluble or at the cellular membrane, contribute to counteracting the enhancement of RAAS by cardiovascular disorders. In this regard, it is noticeable that SACE2 levels were related to long-term cardiovascular death in the HF cohort, suggesting that sACE2 elevation is related to a marked deterioration of the cardiovascular system. High levels of sACE2 can help to predict the bad evolution of patients with HF, and it could be used from the clinical point of view.

This association between prognosis and SACE2 was not observed in the ACS cohort. In this cohort, sACE2 levels were significantly related to age and glycaemic parameters. Elevated fasting glucose plasma levels have been associated with an increased risk of myocardial infarction [39], which might explain the highest levels of glucose found in the ACS compared to the HF cohort. So, the association of sACE2 levels to glycaemic parameters could also mark the pathophysiologic evolution after an ACS, but further research is needed to clarify this issue. 


\section{Limitations}

This is a unicentric, prospective and observational study with the limitations inherent to this type of study design. The design of the study does not allow conclusions about the causality of different sACE2 levels in HF and ACS populations. The number of patients included is small but comparable to other studies that assessed similar objectives and outcomes, and the results are statistically significant. Therefore, we believe that this issue will have future clinical relevance. Second, our study was made only in patients with HF or ACS, so the findings might be different in other cardiovascular patients. Third, our study was performed in ambulatory HF patients, so the extrapolation of our results to patients with acute HF would need to be supported by appropriate data collection. Finally, the results of the in vitro experiments in HUVEC with cardiovascular drugs cannot be directly extrapolated to clinical use. One of the reasons for this is that our experiments with endothelial cells were made in static conditions, whereas the endothelium is always exposed to blood flow. We could not do these experiments under flow conditions, so this is a limitation of the present work.

\section{Conclusions}

Higher levels of sACE2 were observed in patients with HF than in those with ACS, independently of age and gender. These higher levels were related to long-term cardiac death in the HF cohort. However, no such associations were observed in the ACS cohort, where sACE2 levels were only related to age and glycaemic parameters. The levels of sACE2 were not affected by ACEI medication in the population under study. Still, ARB and $\beta$-blockers were associated with higher levels of sACE2, and both types of drugs enhanced ACE2 and SACE2 expression on human endothelial cells in vitro.

Supplementary Information The online version contains supplementary material available at https://doi.org/10.1007/s00109-021-02129-4.

Author contribution Conceptualisation: JRGJ, AVR, JMGA, SE, EA; investigation/data acquisition: CA, MCS, RMA, MGP; writing-original draft: CA, SE, EA; writing - review and editing: all the authors; funding acquisition: JRGJ, SE, EA.

Funding This study was supported by the Plan Nacional Español de I + D, 2008-2011 and the Instituto de Salud Carlos III-Subdirección General de Evaluación y Fomento de la Investigación, ISCIII/ PI14/01140/Cofinanced FEDER. Axudas para a consolidación e estructuración de unidades de investigación competitivas, Xunta de Galicia (Grant Number ED431B 2016/022).
Data availability Not applicable.

\section{Declarations}

Conflict of interest The authors declare no competing interests.

Ethical approval The study was approved by our local Ethics Committee for Human Studies and in accordance with the 1975 Declaration of Helsinki and subsequent amendments (Registry no. 2008/392).

\section{References}

1. South AM, Shaltout HA, Washburn LK, Hendricks AS, Diz DI, Chappell MC (2019) Fetal programming and the angiotensin-(1-7) axis: a review of the experimental and clinical data. Clin Sci (Lond) 133:55-74. https://doi.org/10.1042/CS20171550

2. Trojanowicz B, Ulrich C, Kohler F, Bode V, Seibert E, Fiedler R, Girndt M (2017) Monocytic angiotensin-converting enzyme 2 relates to atherosclerosis in patients with chronic kidney disease. Nephrol Dial Transplant 32:287-298. https://doi.org/10.1093/ndt/ gfw206

3. Donoghue M, Hsieh F, Baronas E, Godbout K, Gosselin M, Stagliano N, Donovan M, Woolf B, Robison K, Jeyaseelan R, Breitbart RE, Acton S (2000) A novel angiotensin-converting enzyme-related carboxypeptidase (ACE2) converts angiotensin I to angiotensin 1-9. Circ Res 87:E1-9. https://doi.org/10.1161/01. res.87.5.e1

4. Sama IE, Ravera A, Santema BT, van Goor H, Ter Maaten JM, Cleland JGF, Rienstra M, Friedrich AW, Samani NJ, Ng LL, Dickstein K, Lang CC, Filippatos G, Anker SD, Ponikowski P, Metra M, van Veldhuisen DJ, Voors AA (2020) Circulating plasma concentrations of angiotensin-converting enzyme 2 in men and women with heart failure and effects of renin-angiotensin-aldosterone inhibitors. Eur Heart J 41:1810-1817. https://doi.org/10. 1093/eurheartj/ehaa373

5. Epelman S, Tang WH, Chen SY, Van Lente F, Francis GS, Sen S (2008) Detection of soluble angiotensin-converting enzyme 2 in heart failure: insights into the endogenous counter-regulatory pathway of the renin-angiotensin-aldosterone system. J Am Coll Cardiol 52:750-754. https://doi.org/10.1016/j.jacc.2008.02.088

6. Epelman S, Shrestha K, Troughton RW, Francis GS, Sen S, Klein AL, Tang WH (2009) Soluble angiotensin-converting enzyme 2 in human heart failure: relation with myocardial function and clinical outcomes. J Card Fail 15:565-571. https://doi.org/10.1016/j.cardf ail.2009.01.014

7. Ramchand J, Patel SK, Srivastava PM, Farouque O, Burrell LM (2018) Elevated plasma angiotensin converting enzyme 2 activity is an independent predictor of major adverse cardiac events in patients with obstructive coronary artery disease. PLoS ONE 13:e0198144. https://doi.org/10.1371/journal.pone.0198144

8. Walters TE, Kalman JM, Patel SK, Mearns M, Velkoska E, Burrell LM (2017) Angiotensin converting enzyme 2 activity and human atrial fibrillation: increased plasma angiotensin converting enzyme 2 activity is associated with atrial fibrillation and more advanced left atrial structural remodelling. Europace 19:1280 1287. https://doi.org/10.1093/europace/euw246

9. Ramchand J, Patel SK, Kearney LG, Matalanis G, Farouque O, Srivastava PM, Burrell LM (2020) Plasma ACE2 activity predicts mortality in aortic stenosis and is associated with severe myocardial fibrosis. JACC Cardiovasc Imaging 13:655-664. https://doi. org/10.1016/j.jcmg.2019.09.005 
10. Ferrario CM, Jessup J, Chappell MC, Averill DB, Brosnihan KB, Tallant EA, Diz DI, Gallagher PE (2005) Effect of angiotensinconverting enzyme inhibition and angiotensin II receptor blockers on cardiac angiotensin-converting enzyme 2. Circulation 111:2605-2610. https://doi.org/10.1161/CIRCULATIONAHA. 104.510461

11. Narula S, Yusuf S, Chong M, Ramasundarahettige C, Rangarajan S, Bangdiwala SI, van Eikels M, Leineweber K, Wu A, Pigeyre M, Pare G (2020) Plasma ACE2 and risk of death or cardiometabolic diseases: a case-cohort analysis. Lancet 396:968-976. https://doi. org/10.1016/S0140-6736(20)31964-4

12. Koka V, Huang XR, Chung AC, Wang W, Truong LD, Lan HY (2008) Angiotensin II up-regulates angiotensin I-converting enzyme (ACE), but down-regulates ACE2 via the AT1-ERK/p38 MAP kinase pathway. Am J Pathol 172:1174-1183. https://doi. org/10.2353/ajpath.2008.070762

13. Hu XS, Xie XD, Wang XX, Zeng CL, Ni YM, Yu GW, Chen JZ (2007) Effects of angiotensin converting enzyme inhibitor on the expression of angiotensin converting enzyme 2 in atrium of patients with atrial fibrillation. Zhonghua Xin Xue Guan Bing Za Zhi 35:625-628

14. Goulter AB, Goddard MJ, Allen JC, Clark KL (2004) ACE2 gene expression is up-regulated in the human failing heart. BMC Med 2:19. https://doi.org/10.1186/1741-7015-2-19

15. Lebek S, Tafelmeier M, Messmann R, Provaznik Z, Schmid C, Maier LS, Birner C, Arzt M, Wagner S (2020) ACE inhibitor/ angiotensin II receptor blocker treatment and hemodynamic factors are associated with increased cardiac mRNA expression of ACE2 in patients with cardiovascular disease. Eur J Heart Fail. https://doi.org/10.1002/ejhf.2020

16. Ferrario CM (2005) Myocardial infarction increases ACE2 expression in rat and humans. Eur Heart J 26:1141-1143. https:// doi.org/10.1093/eurheartj/ehi256

17. Oudit GY, Liu GC, Zhong J, Basu R, Chow FL, Zhou J, Loibner H, Janzek E, Schuster M, Penninger JM, Herzenberg AM, Kassiri Z, Scholey JW (2010) Human recombinant ACE2 reduces the progression of diabetic nephropathy. Diabetes 59:529-538. https:// doi.org/10.2337/db09-1218

18. Ohtsuki M, Morimoto SI, Izawa H, Ismail TF, Ishibashi-Ueda $\mathrm{H}$, Kato Y, Horii T, Isomura T, Suma H, Nomura M, Hishida H, Kurahashi H, Ozaki Y (2010) Angiotensin converting enzyme 2 gene expression increased compensatory for left ventricular remodeling in patients with end-stage heart failure. Int J Cardiol 145:333-334. https://doi.org/10.1016/j.ijcard.2009.11.057

19. Zisman LS, Keller RS, Weaver B, Lin Q, Speth R, Bristow MR, Canver CC (2003) Increased angiotensin-(1-7)-forming activity in failing human heart ventricles: evidence for upregulation of the angiotensin-converting enzyme Homologue ACE2. Circulation 108:1707-1712. https://doi.org/10.1161/01.CIR.0000094734. 67990.99

20. Kawai T, Elliott KJ, Scalia R, Eguchi S (2021) Contribution of ADAM17 and related ADAMs in cardiovascular diseases. Cell Mol Life Sci 78:4161-4187. https://doi.org/10.1007/ s00018-021-03779-w

21. Young MJ, Clyne CD, Chapman KE (2020) Endocrine aspects of ACE2 regulation: RAAS, steroid hormones and SARS-CoV-2. J Endocrinol 247:R45-R62. https://doi.org/10.1530/JOE-20-0260

22. Behl T, Kaur I, Bungau S, Kumar A, Uddin MS, Kumar C, Pal G, Sahil SK, Zengin G, Arora S (2020) The dual impact of ACE2 in COVID-19 and ironical actions in geriatrics and pediatrics with possible therapeutic solutions. Life Sci 257:118075. https://doi. org/10.1016/j.lfs.2020.118075

23. Sharma RK, Li J, Krishnan S, Richards EM, Raizada MK, Mohandas R (2021) Angiotensin-converting enzyme 2 and COVID-19 in cardiorenal diseases. Clin Sci (Lond) 135:1-17. https://doi.org/ $10.1042 / C S 20200482$
24. Danser AHJ, Epstein M, Batlle D (2020) Renin-angiotensin system blockers and the COVID-19 pandemic: at present there is no evidence to abandon renin-angiotensin system blockers. Hypertension 75:1382-1385. https://doi.org/10.1161/HYPERTENSI ONAHA.120.15082

25. Dzau VJ, Antman EM, Black HR, Hayes DL, Manson JE, Plutzky J, Popma JJ, Stevenson W (2006) The cardiovascular disease continuum validated: clinical evidence of improved patient outcomes: part I: Pathophysiology and clinical trial evidence (risk factors through stable coronary artery disease). Circulation 114:2850 2870. https://doi.org/10.1161/CIRCULATIONAHA.106.655688

26. Dzau VJ, Antman EM, Black HR, Hayes DL, Manson JE, Plutzky J, Popma JJ, Stevenson W (2006) The cardiovascular disease continuum validated: clinical evidence of improved patient outcomes: part II: Clinical trial evidence (acute coronary syndromes through renal disease) and future directions. Circulation 114:2871-2891. https://doi.org/10.1161/CIRCULATIONAHA.106.655761

27. Raposeiras-Roubin S, Rodino-Janeiro BK, Grigorian-Shamagian L, Moure-Gonzalez M, Seoane-Blanco A, Varela-Roman A, Alvarez E, Gonzalez-Juanatey JR (2010) Soluble receptor of advanced glycation end products levels are related to ischaemic aetiology and extent of coronary disease in chronic heart failure patients, independent of advanced glycation end products levels: new roles for soluble RAGE. Eur J Heart Fail 12:1092-1100. https://doi.org/ 10.1093/eurjhf/hfq117

28. Raposeiras-Roubin S, Rodino-Janeiro BK, Paradela-Dobarro B, Grigorian-Shamagian L, Garcia-Acuna JM, Aguiar-Souto P, Jacquet-Hervet M, Reino-Maceiras MV, Gonzalez-Juanatey JR, Alvarez E (2013) Fluorescent advanced glycation end products and their soluble receptor: the birth of new plasmatic biomarkers for risk stratification of acute coronary syndrome. PLoS ONE 8:e74302. https://doi.org/10.1371/journal.pone.0074302

29. Paradela-Dobarro B, Agra RM, Ãlvarez L, Varela-Román A, García-Acuña JM, González-Juanatey JR, Álvarez E, GarcíaSeara FJ (2019) The different roles for the advanced glycation end products axis in heart failure and acute coronary syndrome settings. Nutr Metab Cardiovasc Dis 29:1050-1060. https://doi. org/10.1016/j.numecd.2019.06.014

30. Ponikowski P, Voors AA, Anker SD, Bueno H, Cleland JG, Coats AJ, Falk V, Gonzalez-Juanatey JR, Harjola VP, Jankowska EA, Jessup M, Linde C, Nihoyannopoulos P, Parissis JT, Pieske B, Riley JP, Rosano GM, Ruilope LM, Ruschitzka F, Rutten FH, van der Meer P (2016) 2016 ESC Guidelines for the diagnosis and treatment of acute and chronic heart failure: the Task Force for the diagnosis and treatment of acute and chronic heart failure of the European Society of Cardiology (ESC)Developed with the special contribution of the Heart Failure Association (HFA) of the ESC. Eur Heart J 37:2129-2200. https://doi.org/10.1093/eurhe artj/ehw128

31. Paradela-Dobarro B, Rodiño-Janeiro BK, Alonso J, RaposeirasRoubín S, González-Peteiro M, González-Juanatey JR, Álvarez E (2016) Key structural and functional differences between early and advanced glycation products. J Mol Endocrinol 56:23-37. https:// doi.org/10.1530/JME-15-0031

32. Patel VB, Clarke N, Wang Z, Fan D, Parajuli N, Basu R, Putko B, Kassiri Z, Turner AJ, Oudit GY (2014) Angiotensin II induced proteolytic cleavage of myocardial ACE2 is mediated by TACE/ ADAM-17: a positive feedback mechanism in the RAS. J Mol Cell Cardiol 66:167-176. https://doi.org/10.1016/j.yjmcc.2013.11.017

33. Ortiz-Pérez JT, Riera M, Bosch X, De Caralt TM, Perea RJ, Pascual J, Soler MJ (2013) Role of circulating angiotensin converting enzyme 2 in left ventricular remodeling following myocardial infarction: a prospective controlled study. PLoS ONE 8:e61695. https://doi.org/10.1371/journal.pone.0061695

34. Hoffmann M, Kleine-Weber H, Schroeder S, Kruger N, Herrler T, Erichsen S, Schiergens TS, Herrler G, Wu NH, Nitsche A, 
Muller MA, Drosten C, Pohlmann S (2020) SARS-CoV-2 cell entry depends on ACE2 and TMPRSS2 and is blocked by a clinically proven protease inhibitor. Cell 181:271-280. https://doi.org/ 10.1016/j.cell.2020.02.052

35. Heurich A, Hofmann-Winkler H, Gierer S, Liepold T, Jahn O, Pohlmann S (2014) TMPRSS2 and ADAM17 cleave ACE2 differentially and only proteolysis by TMPRSS 2 augments entry driven by the severe acute respiratory syndrome coronavirus spike protein. J Virol 88:1293-1307. https://doi.org/10.1128/JVI.02202-13

36. Dambha-Miller H, Albasri A, Hodgson S, Wilcox CR, Khan S, Islam N, Little P, Griffin SJ (2020) Currently prescribed drugs in the UK that could upregulate or downregulate ACE2 in COVID19 disease: a systematic review. BMJ Open 10:e040644. https:// doi.org/10.1136/bmjopen-2020-040644

37. Pedrosa MA, Valenzuela R, Garrido-Gil P, Labandeira CM, Navarro G, Franco R, Labandeira-Garcia JL, Rodriguez-Perez AI (2021) Experimental data using candesartan and captopril indicate no double-edged sword effect in COVID-19. Clin Sci (Lond) 135:465-481. https://doi.org/10.1042/CS20201511

38. Chirinos JA, Cohen JB, Zhao L, Hanff T, Sweitzer N, Fang J, Corrales-Medina V, Anmar R, Morley M, Zamani P, Bhattacharya P, Brandimarto J, Jia Y, Basso MD, Wang Z, Ebert C, Ramirez-Valle F, Schafer PH, Seiffert D, Gordon DA, Cappola T (2020) Clinical and proteomic correlates of plasma ACE2 (angiotensin-converting enzyme 2) in human heart failure. Hypertension 76:1526-1536. https://doi.org/10.1161/HYPERTENSIONAHA.120.15829
39. Ryden L, Grant PJ, Anker SD, Berne C, Cosentino F, Danchin N, Deaton C, Escaned J, Hammes HP, Huikuri H, Marre M, MarX N, Mellbin L, Ostergren J, Patrono C, Seferovic P, Uva MS, Taskinen MR, Tendera M, Tuomilehto J, Valensi P, Zamorano JL, Achenbach S, Baumgartner H, Bax JJ, Bueno H, Dean V, Erol C, Fagard R, Ferrari R, Hasdai D, Hoes AW, Kirchhof P, Knuuti J, Kolh P, Lancellotti P, Linhart A, Nihoyannopoulos P, Piepoli MF, Ponikowski P, Sirnes PA, Tamargo JL, Torbicki A, Wijns W, Windecker S, De Backer G, Ezquerra EA, Avogaro A, Badimon L, Baranova E, Betteridge J, Ceriello A, Funck-Brentano C, Gulba DC, Kjekshus JK, Lev E, Mueller C, Neyses L, Nilsson PM, Perk J, Reiner Z, Sattar N, Schachinger V, Scheen A, Schirmer H, Stromberg A, Sudzhaeva S, Viigimaa M, Vlachopoulos C, Xuereb RG (2013) ESC Guidelines on diabetes, pre-diabetes, and cardiovascular diseases developed in collaboration with the EASD: the Task Force on diabetes, pre-diabetes, and cardiovascular diseases of the European Society of Cardiology (ESC) and developed in collaboration with the European Association for the Study of Diabetes (EASD). Eur Heart J 34:3035-3087. https://doi.org/10.1093/ eurheartj/eht108

Publisher's Note Springer Nature remains neutral with regard to jurisdictional claims in published maps and institutional affiliations. 